Estudos RBEP

\title{
Políticas de organização curricular para a escola pública em tempo integral: as lições de uma experiência
}

Rosimar Serena Siqueira Esquinsani

\section{Resumo}

Apresenta resultados de pesquisa qualitativa realizada em uma rede pública municipal de ensino do interior sul-rio-grandense, com o objetivo de acompanhar a implantação de escolas em tempo integral, focando, entre outros aspectos, a organização curricular para essa realidade. A pesquisa foi desenvolvida por meio da análise de conteúdo aplicada a fontes documentais e à revisão bibliográfica, dando conta de uma administração quadrienal (2005-2008). Durante o estudo, constatou-se que, em relação ao tema currículo, emergem indefinições que vão desde o conceito de educação integral até o elenco de conteúdos desenvolvidos. Como conclusão, o texto aponta que a escola em tempo integral tem uma significação expressa, em larga medida, pelo currículo conduzido/ organizado. Assim, definir questões mínimas para o currículo nas/para as escolas em tempo integral é importante tarefa política e pedagógica.

Palavras-chave: tempo integral; currículo; escola pública. 


\section{Abstract \\ Curriculum organization policies for full-time public schools: lessons from one experience}

This article presents findings from a qualitative research conducted in the municipal public school system of a town in the interior of Rio Grande do Sul state, aiming at experiencing the implementation process of fulltime schools, with emphasis on the organization of a new curriculum. The research was made using content analysis and surveying the relevant literature, referring to a four-year administration (2005-2008). During the study, there emerged imprecision related to the theme curriculum, that range from the concept of full-time education to the list of the usual curriculum subjects. As a conclusion, the paper indicates that full-time schools are largely driven by their organized curriculum. Therefore, setting curriculum standards for full-time schooling is an important pedagogical and political task.

Keywords: full-time, curriculum, public school.

Ao menos discursivamente, a maioria dos governos, nos distintos níveis federados, assume o compromisso intransigente da qualidade na escola pública. Inúmeros deles, entretanto, para além da esfera do discurso, também edificam políticas (ações, experiências, programas) que, de fato, favorecem a qualidade dessa escola.

Entre as experiências que visam à qualidade da escola pública brasileira, sazonalmente, concretizam-se instituições cuja organização curricular se dá em regime de tempo integral, normalmente vinculada ao uso pelo mesmo grupo discente de dois turnos regulares, entremeados por alimentação, higiene e atividades de recreação. O tema é recorrente e, via de regra, encontra resistências na cultura instaurada de turnos escolares dispostos em quatro horas diárias, já cristalizados em nosso modelo de escolarização.

Oportunamente, entretanto, experiências de ensino em tempo integral têm mostrado fôlego para superar as barreiras da escolarização congestionada em turnos sucessivos de alunos, aglomerados não em dias letivos, mas em meios dias letivos (Teixeira, 1994), e apresentar propostas qualitativas de educação pública.

$\mathrm{Na}$ esteira da afirmação anterior e no encalço de experiências positivas, concebi uma pesquisa qualitativa em uma rede pública municipal de ensino, objetivando acompanhar o processo de implementação de 
escolas em tempo integral (edificadas pelo prolongamento de permanência do aluno na instituição), desenvolvido na rede de escolas mantidas por um município de médio porte no interior sul-rio-grandense. Para este texto, entretanto, foi pinçado um dos aspectos atinentes a esta pesquisa: a organização curricular para a realidade em questão. Há, pois, um recorte temático intencional que transpassa o texto apresentado: o currículo.

A pesquisa foi desenvolvida dentro de duas abordagens: a análise de conteúdo advinda de fontes documentais (jornais de circulação local, atas de reuniões e relatórios elaborados a partir de encontros de formação com professores e gestores) e a revisão bibliográfica sobre a temática.

No encerramento do período de pesquisa - cujo hiato temporal deu conta de uma administração quadrienal, de 2005 a 2008 -, a rede municipal de ensino examinada contava com 37 escolas de ensino fundamental, que comportavam 11.926 alunos, atendidos por 1.065 docentes (Passo Fundo, 2008). Nessa rede, 12,5\% das escolas de ensino fundamental estavam organizadas em regime de tempo integral.

Essas escolas em tempo integral estão localizadas em bairros periféricos, entendendo-se por periferia os bairros e as vilas que se constituem nos limites das cidades, muitas vezes sem condições de urbanização adequadas, e aos quais acorrem famílias com menor poder aquisitivo, "expulsas" do centro urbano pela especulação imobiliária que inflaciona as residências mais centrais. Tais escolas acolheram, em 2008, 442 alunos, distribuídos em 21 turmas e atendidos por 41 professores.

Todavia, a forma de organização da experiência de ensino em tempo integral não foi similar em todas as instituições envolvidas no estudo, pois havia escolas organizadas em dois turnos regulares ligados por um programa de alimentação escolar; escolas que disciplinavam o tempo integral em oficinas oferecidas em turno inverso ao da escolarização formal (contraturno); além de uma escola que, excepcionalmente, funcionava das 12 às 18 horas.

Importa, ainda, fazer dois destaques: inicialmente, cumpre informar que classifico a organização escolar em tempo integral acompanhada como experiência, pois ela careceu de uma legislação educacional que a amparasse, atrelando-se a programas de governo e não a políticas públicas. Um segundo destaque diz respeito à compreensão acerca da dimensão política de um currículo, pois a forja dele nada mais é do que

\footnotetext{
a expressão do equilíbrio de interesses e forças que gravitam sobre o sistema educativo num dado momento, enquanto que através deles se realizam os fins da educação no ensino escolarizado [...] é uma opção historicamente configurada, que se sedimentou dentro de uma determinada trama cultural, política, social e escolar, está carregado, portanto, de valores e pressupostos... (Gimeno Sacristán, 2000, p. 17).
}

Dessa forma, monitorar uma experiência de escolarização formal, visando extrair dela elementos para a discussão curricular, leva o pesquisador imperiosamente pelos caminhos do poder e da conjugação de forças em torno de um projeto educativo. 
Após o monitoramento do desenvolvimento da experiência (Administração 2005-2008), foi possível constatar que, em relação ao tema currículo para a escola em tempo integral, a experiência mostrou algumas indefinições que, se problematizadas, podem favorecer e progredir no debate acerca desse modelo de organização escolar/curricular.

A primeira indefinição pega carona no conceito de educação em tempo integral. A maioria dos envolvidos (alunos, pais, professores, assessores e gestores) conceitua educação integral como educação em turno integral, associando diretamente tempo de permanência em sala de aula (ou outros espaços considerados pedagógicos, como campo de futebol, ginásio de esportes, biblioteca, museu, zoológico etc.) com o desenvolvimento de uma educação integral, conduzida supostamente por um currículo integral (Esquinsani, 2008).

Nessa linha de raciocínio, pequenos ordenamentos e ajustes na disposição dos conteúdos, ou passeios e atividades lúdicas em turno inverso, dariam conta da perspectiva integral do currículo, como se ele tivesse o poder de autogestão, sem a interferência dos sujeitos envolvidos. Sob essa lógica, bastaria batizá-lo como currículo integral, inserir passeios ou atividades diferenciadas e modificar a grade de disciplinas/componentes curriculares ofertados para que ele assumisse ares de integral.

Nesse sentido, e a despeito da ideia recorrente de que quando um currículo é definido estão descritas "a concretização das funções da própria escola e a forma particular de enfocá-las num momento histórico e social determinado, para um nível ou modalidade de educação, numa trama institucional" (Gimeno Sacristán, 2000, p. 15), palpável nos discursos encetados (Esquinsani, 2007), o orquestramento das diferentes atividades inerentes ao currículo escolar mostra-se, na experiência examinada, embasada em um simples (re)arranjo de conteúdos, tempos e espaços.

Justo por essa razão, a característica mais evidente das escolas analisadas consiste na crença de que quanto maior o tempo de permanência da criança na escola, mais condições de apropriação formal dos conteúdos escolares ela terá, como se a aprendizagem fosse uma dádiva, um "mimo" ofertado ao aluno por meio da simples ampliação do tempo escolar, incrementado por uma ou outra atividade "diferenciada".

Uma segunda indefinição versa sobre a "clientela" para quem se estrutura e a partir de quem se propõe o currículo (ou as atividades, em sentido mais estrito). Importa salientar que, atualmente, "as questões curriculares estão intimamente conectadas aos problemas sociais" (Berticelli, 2001, p. 175), o que faz com que o debate acerca do currículo desenvolvido em escolas de tempo integral assuma relevância singular.

As escolas em tempo integral estão localizadas em bairros periféricos da cidade, o que favorece a vinculação de tal modelo de escolarização a um certo compromisso político (e opção administrativa) para com as comunidades de alto risco e vulnerabilidade social. Grosso modo, a escola em tempo integral termina por assumir um caráter iminente de "guarda" integral a partir de um olhar assistencialista, em detrimento de aspectos pedagógicos inerentes a tal organização curricular. 
Fruto desse contexto assistencialista, um exame acurado do tema permite afirmar que os sujeitos diretamente envolvidos na experiência (pais, professores e alunos) também encaram o currículo da escola em tempo integral equivocadamente como integral, supondo uma falsa integralidade de atividades pela simples dilatação do período de permanência do aluno na escola. A inovação parece estar em uma mera hierarquização diferenciada dos mesmos componentes curriculares e no alargamento do tempo de permanência.

A implementação de uma estratégia intersubjetiva de ação curricular não pode ser entendida separadamente das condições reais de seu desenvolvimento e, por isso mesmo, entender o currículo num sistema educativo requer prestar atenção às práticas políticas e administrativas que se expressam em seu desenvolvimento, às condições estruturais, organizativas, materiais, dotação de professorado, à bagagem de idéias e significado que lhe dão forma e que o modelam em sucessivos passos de transformação. (Gimeno Sacristán, 2000, p. 21).

O discurso social que justifica tal modelo de organização escolar é fundado, por vezes, unicamente na necessidade de atendimento a alunos em situação de risco e vulnerabilidade social em dois turnos regulares, gerando um baixo investimento em questões pedagógicas, como o currículo.

Uma política educacional e, sobremaneira, uma política curricular não se materializam apenas com intenções e propagandas. Se do ponto de vista do discurso social a escola em tempo integral é absolutamente defensável, tal discurso não sustenta-se como justificativa plausível para a aplicação de qualquer modelo dessa escola. A qualidade de uma experiência de escolarização em tempo integral advém, em grande medida, dos investimentos feitos na escola, bem como do caráter inovador de sua proposta pedagógica. Se não há uma clara intenção pedagógica ou a alocação de recursos financeiros e humanos para o desenvolvimento da experiência, a simples propaganda de uma suposta inovação pela permanência estendida dos alunos na instituição não tem o condão de transformar em integral um currículo (Esquinsani, 2008), além de ser enganoso e proselitista.

A terceira indefinição reside na sensível dificuldade em pensar uma proposta de organização curricular em tempo integral a partir da interdisciplinaridade, da ligação entre as atividades, sendo que as definições curriculares são alocadas em fatores externos, como os condicionantes temporais, sem um tratamento adequado do tema currículo a partir de uma proposta interdisciplinar.

A prova mais contundente acerca da afirmação acima consiste na separação institucional entre professores que atuam no contraturno e o professor "titular" da classe, que atua no turno regular. Na maioria das vezes, o planejamento das atividades para a mesma turma é feito de forma isolada, cada qual dando conta exclusivamente do seu turno de trabalho (Esquinsani, 2007).

Aqui se encontra um ponto nevrálgico de indefinição curricular: se até mesmo o planejamento é compartimentalizado, segmentado, como pensar em um currículo, de fato, integral ou interdisciplinar? 
Nesse contexto, o currículo oficial até pode receber o adereço de "integral", sendo que as oficinas e as atividades do contraturno teriam um caráter complementar, adicional ao que é desenvolvido no turno regular. Todavia, o currículo praticado, também denominado "currículo em uso" (Moreira, 2001), ou o efetivamente desenvolvido em sala de aula, oficinas, aulas de reforço e outros espaços educativos, não atenta para a integralidade (ontológica) do que é desenvolvido na escola em tempo integral.

Como quarta indefinição, importa destacar o papel do professor que dará, em última instância, a condução ao currículo dentro das escolas envolvidas na experiência.

O "nome", o "título" de uma experiência não têm força para, isoladamente, modificar práticas curriculares. Novos olhares não vêm por decreto, mas por crença nas possibilidades do novo, tendo em vista que "o currículo é uma práxis antes que um objeto estático emanado de um modelo coerente de pensar a educação ou as aprendizagens necessárias das crianças e dos jovens que tampouco se esgota na parte explícita do projeto de socialização cultural nas escolas" (Gimeno Sacristán, 2000, p. 15).

Destarte, na concretização de um currículo integral, o professor desempenha papel singular, tanto na formulação da proposta (nos seus espaços de autonomia e decisão) quanto no acompanhamento dos resultados. Ou seja, o êxito ou o fracasso de uma experiência curricular inovadora depende, em grande medida, da adesão do corpo docente, pois

ninguém pode ensinar verdadeiramente se não ensina alguma coisa que seja verdadeira ou válida a seus próprios olhos. Esta noção de valor intrínseco da coisa ensinada, tão difícil de definir e de justificar quanto de refutar ou rejeitar, está no próprio centro daquilo que constitui a especificidade da intenção docente como projeto de comunicação formadora. (Forquin, 1993, p. 9).

Assim, o professor precisa assumir, sem falsos proselitismos, seu protagonismo em relação ao que ocorre dentro da escola, pois ele é o ator principal, se não na elaboração, com certeza na execução e na avaliação de uma proposta curricular.

Entretanto, interessa sublinhar que, na experiência analisada, os professores que trabalham no chamado contraturno são, em sua grande maioria, estagiários de cursos de licenciatura das instituições de ensino superior da região, sem vínculo empregatício formal, situação que os força a uma atuação competente, mas de caráter provisório (Passo Fundo, 2008).

A regularização da situação do pessoal docente seria um passo interessante na busca do perfil de um profissional protagonista dos destinos da escola e dos projetos por ela encampados.

Uma quinta e última indefinição manifesta-se no descompasso percebido entre o que se pretende por um currículo integral e o que realmente ocorre nas escolas. Via de regra, as atividades estendidas ao contraturno poderiam ser realizadas no chamado turno regular, sem grandes "sustos" ou impactos. Não há grandes novidades, à exceção da metodologia utilizada no contraturno (Esquinsani, 2007). 
As atividades do contraturno são supletivas em relação ao turno regular. Os turnos não são complementares ou mesmo entrosados, o que gera a ideia (e a concretização dessa ideia) de que o que é realizado em dois turnos poderia, sem surpresas, ser realizado em apenas um.

Percebe-se nitidamente que a boa vontade dos professores envolvidos é concreta, mas limitada pelo entendimento de que atividades lúdicas e planejamento para o contraturno são sinônimos de currículo apropriado para a escola em tempo integral (Esquinsani, 2008).

\section{Algumas apostas}

Se existem indefinições acerca do currículo desenvolvido em escolas de tempo integral no estudo analisado, elas têm como uma das gêneses o pioneirismo na organização das instituições e servem sim, com muita propriedade, como lições para o aprimoramento da experiência.

Nesse sentido, não há razões para não apostar na escola em tempo integral, que pode ser uma interessante forma qualitativa de gerenciamento e organização da escola pública. Se existem algumas indefinições, também existem expectativas e possibilidades de superação, em especial no tema (ou a começar pelo tema) currículo.

Ao impelir, compulsoriamente, alunos e professores a estenderem o período de permanência na escola, a experiência em tela acabou por agregar a dilatação do tempo ao fator qualidade, como se um dependesse do outro, em uma falsa simbiose.

Como ruptura a essa construção, é possível apostar em um trabalho voltado para definições curriculares a partir de um estudo conceitual e de uma proposta interdisciplinar, a fim de romper com o fator tempo como o único responsável por um currículo inovador, em uma experiência que se pretende inovadora e qualitativa.

Se o professor parte da crença estanque de que a simples dilatação do tempo já é condicionante de um currículo integral, via de regra, ele assim será na concepção da escola (que não corresponde a consecução de um currículo integral de fato). Um currículo não existe em si mesmo, não existe no papel, mas na prática cotidiana, no dia a dia.

Na mesma direção,

em nossas atividades cotidianas, os currículos que criamos misturam elementos das propostas formais e organizadas com as possibilidades que temos de implantá-las e o acordo ou desacordo que temos sobre elas. Por sua vez, essas possibilidades se relacionam com aquilo que sabemos e em que acreditamos, ao mesmo tempo em que são definidas na dinâmica de cada turma, dos saberes dos alunos, das circunstâncias de cada dia de trabalho. (Alves, Oliveira, 2002, p. 96).

Contudo, assumo ainda a defesa da escola em tempo integral. Se as concepções de currículo integral estão afastadas da escola, tomada em sua integralidade apenas pelo horário estendido, tal situação não é 
"privilégio" da experiência examinada. Se o currículo não é percebido em sua integralidade, em boa medida, deve-se à cultura instituída de assim percebê-lo.

Também a educação por meio da escola em tempo integral tem uma significação para seus articuladores, propositores e defensores, significado que se expressa, em larga medida, pelo currículo conduzido/organizado. Diante dessa informação, acertar o passo e definir questões mínimas para organizar o currículo nas/para as escolas em tempo integral passa a ser uma importante tarefa política e pedagógica.

A organização escolar pode ser um balizador de qualidade para redes e sistemas públicos de ensino? Sim, com certeza. Projetada para atender demandas sociais e educacionais em situações de risco e vulnerabilidade, mesmo com mazelas aparentes a escola pública em tempo integral é uma tentativa concreta de investimento na qualidade dos processos educativos, ainda que sobre ela recaiam indefinições curriculares.

\section{Referências bibliográficas}

ALVES, N.; OLIVEIRA, I. B. de. Uma história da contribuição dos estudos do cotidiano escolar ao campo de currículo. In: LOPES, A. C.; MACEDO, E. (Orgs.). Currículo: debates contemporâneos. São Paulo: Cortez, 2002. p. 78-102.

BERTICELLI, I. A. Currículo: tendências e filosofia. In: COSTA, M. V. (Org.). O currículo nos limiares do contemporâneo. 3. ed. Rio de Janeiro: DP\&A, 2001. p. 159-176.

ESQUINSANI, Rosimar S.S. Relatório de pesquisa I do projeto "As políticas educacionais de expansão qualitativa da escola pública: a experiência da escola em tempo integral sob o olhar de Anísio Teixeira", financiado pelo CNPq. 2006.

. Relatório de pesquisa II do projeto "As políticas educacionais de expansão qualitativa da escola pública: a experiência da escola em tempo integral sob o olhar de Anísio Teixeira", financiado pelo CNPq. 2007.

. Relatório de pesquisa III do projeto "As políticas educacionais de expansão qualitativa da escola pública: a experiência da escola em tempo integral sob o olhar de Anísio Teixeira", financiado pelo CNPq. 2008.

FORQUIN, J. C. Escola e cultura: as bases sociais e epistemológicas do conhecimento escolar. Trad. Guacira Lopes Louro. Porto Alegre: Artes Médicas, 1993. 
GIMENO SACRISTÁN, J. O currículo: uma reflexão sobre a prática. 3. ed. Porto Alegre: ArtMed, 2000.

MOREIRA, A. F. A crise da teoria curricular crítica. In: COSTA, M. V. (Org.). O currículo nos limiares do contemporâneo. 3. ed. Rio de Janeiro: DP\&A, 2001. p. 11-36.

PASSO FUNDO. Secretaria Municipal de Educação. Coordenadoria de Administração. Setor de Registros Escolares. Levantamentos estatísticos. 2008.

TEIXEIRA, Anísio. Educação não é privilégio. 5. ed. Rio de Janeiro: UFRJ, 1994.

Rosimar Serena Siqueira Esquinsani, doutora em Educação pela Universidade do Vale do Rio dos Sinos (Unisinos), é professora e pesquisadora do Programa de Pós-Graduação em Educação da Universidade de Passo Fundo (UPF).

rosimaresquinsani@upf.br

Recebido em 24 de outubro de 2009.

Aprovado em 15 de dezembro de 2009. 